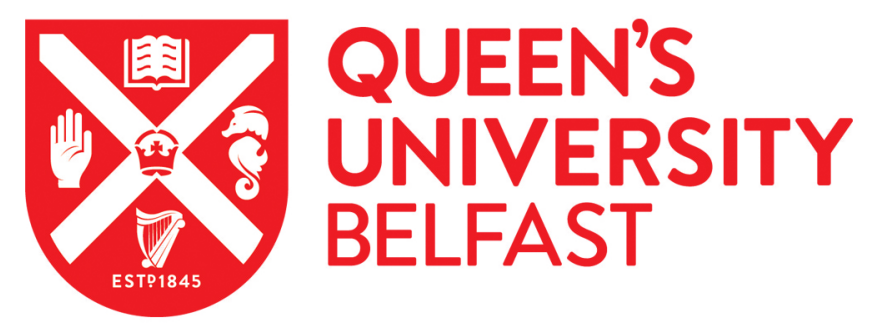

\title{
Packing polymorphism of dapivirine and its impact on the performance of a dapivirine-releasing silicone elastomer vaginal ring
}

\author{
McCoy, C. F., Murphy, D. J., Boyd, P., Derrick, T., Spence, P., Devlin, B., \& Malcolm, R. (2017). Packing \\ polymorphism of dapivirine and its impact on the performance of a dapivirine-releasing silicone elastomer \\ vaginal ring. Journal of Pharmaceutical Sciences, 106(8), 2015-2025. https://doi.org/10.1016/j.xphs.2017.04.026
}

Published in:

Journal of Pharmaceutical Sciences

Document Version:

Peer reviewed version

Queen's University Belfast - Research Portal:

Link to publication record in Queen's University Belfast Research Portal

\section{Publisher rights}

Copyright 2017 Elsevier.

This manuscript is distributed under a Creative Commons Attribution-NonCommercial-NoDerivs License

(https://creativecommons.org/licenses/by-nc-nd/4.0/), which permits distribution and reproduction for non-commercial purposes, provided the author and source are cited.

\section{General rights}

Copyright for the publications made accessible via the Queen's University Belfast Research Portal is retained by the author(s) and / or other copyright owners and it is a condition of accessing these publications that users recognise and abide by the legal requirements associated with these rights.

Take down policy

The Research Portal is Queen's institutional repository that provides access to Queen's research output. Every effort has been made to ensure that content in the Research Portal does not infringe any person's rights, or applicable UK laws. If you discover content in the Research Portal that you believe breaches copyright or violates any law, please contact openaccess@qub.ac.uk. 


\section{Packing polymorphism of dapivirine and its impact on \\ the performance of a dapivirine-releasing silicone \\ elastomer vaginal ring}

8

\author{
Clare F. McCoy ${ }^{1}$, Diarmaid J. Murphy ${ }^{1}$, Peter Boyd ${ }^{1}$, Tiffany Derrick ${ }^{2}$,
} Patrick Spence $^{2}$, Brid Devlin ${ }^{2}$, R. Karl Malcolm ${ }^{1 *}$

7

8

${ }^{I}$ School of Pharmacy, Queen's University Belfast, Belfast BT9 7BL, UK;

${ }^{2}$ International Partnership for Microbicides, Silver Spring, MD 20910, USA

(1)

*Corresponding author. Tel: +44 (0)28 9097 2319; E-mail: k.malcolm@qub.ac.uk

2

3

Short title: Impact of polymorphism on performance of dapivirine vaginal ring

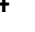

15

Keywords: HIV microbicide; Silicone elastomer vaginal ring; Dapivirine; Formulation

$$
\text { development; Polymorphism }
$$

17

N.B. Red text in this document highlights changes made to the manuscript since the

9




\section{Abstract}

21 A silicone elastomer vaginal ring device providing sustained release over 28 days of the

22 antiretroviral microbicide dapivirine has recently completed Phase III clinical testing and

23 showed moderate protection against HIV acquisition. Here, for the first time, and in support

24 of the product licensure program, we report the impact of dapivirine packing polymorphism

25 on the in vitro performance of the $25 \mathrm{mg}$ dapivirine ring product. Thermal, particle size,

26 powder x-ray diffraction and thermodynamic solubility analyses of dapivirine polymorphic

27 forms I and IV, both of which are persistent at room temperature and with form I being the

28 thermodynamically stable form, were conducted for micronized and non-micronized

29 materials. Matrix-type silicone elastomer vaginal rings were manufactured and the impact

30 of dapivirine polymorphism on key in vitro parameters (compression and tensile behaviour;

31 content assay; in vitro release; residual content assay) was investigated. The data

32 demonstrate that dapivirine packing polymorphism has no significant impact on in vitro

33 performance of the $25 \mathrm{mg}$ dapivirine vaginal ring. 


\section{1. Introduction}

35 Many solid drug substances exist in different crystalline forms - known as packing 36 polymorphs - that differ in their physical properties. ${ }^{1}$ In some cases, these different 37 crystalline forms of the drug substance can significantly affect the pharmacological

38 performance of the drug product. One of the most widely reported examples is the influence

39 of polymorphism on the oral bioavailability of the antiretroviral drug ritonavir. ${ }^{2,3}$ Ritonavir

40 exists in two major crystalline forms - forms I and II. In 1998, the unexpected appearance

41 of the more stable (and therefore less soluble) form II during routine testing of the drug led

42 to compromised oral bioavailability of the drug and ultimately removal of the oral capsule

43 formulation from the market. Since this incident, the U.S. Food and Drug Administration

44 (FDA) has focused increased attention on the potential impact of drug polymorphism on

45 the performance of drug products and the measures taken to ensure that physical properties

46 to not change during shelf life. It is therefore imperative that polymorphism is investigated

47 during the drug product development process. Both the FDA and the International Council

48 for Harmonisation (ICH) have published regulatory documents addressing pharmaceutical 49 polymorphism. ${ }^{4-6}$

50

51 Dapivirine (DPV) is an experimental non-nucleoside reverse transcriptase inhibitor 52 (NNRTI) that is currently being developed as a vaginal microbicide for prevention of 53 sexual transmission of human immunodeficiency virus type 1 (HIV-1). ${ }^{7-12}$ A wide range 54 of formulation strategies have been reported for vaginal administration of DPV, ${ }^{13-18}$ the 55 most advanced and the most promising of which are silicone elastomer vaginal rings. ${ }^{19-33}$ 56 Two Phase III efficacy studies - The Ring Study (IPM027) and APSIRE (MTN-020) - 
57 involving more than 4,500 women volunteers across southern and eastern Africa have

58 recently been completed, designed to support licensure of a monthly matrix-type silicone

59 elastomer vaginal ring containing $25 \mathrm{mg}$ micronized DPV intended for 28-day continuous

60 use (DPV Ring-004). The studies showed approximately 30\% reduced incidence of HIV

61 infection in women compared to a placebo, the first time two studies have confirmed

62 statistically significant efficacy for a HIV microbicide. ${ }^{27,33}$ The lower than anticipated

63 protection rates were attributed to poor user adherence, an ongoing problem that has

64 adversely affected clinical testing of HIV microbicides. ${ }^{33-42}$ Post-hoc analyses of the DPV

65 ring clinical data in The Ring Study and ASPIRE have revealed that rates of protection are

66 very significantly increased $(>60 \%)$ in sub-groups demonstrating increased adherence. ${ }^{27,33}$

67

68 Three crystalline polymorphic forms of DPV have been identified - forms I, II and IV

69 (Figure 1). ${ }^{22} \mathrm{~A}$ dichloromethane hemi-solvate stable up to $130^{\circ} \mathrm{C}$ was originally identified

70 as polymorphic form III. However, dichloromethane is no longer used in the DPV

71 manufacturing process. Therefore, further work with this form was no longer relevant and

72 was not pursued. The current method for chemical synthesis of DPV reproducibly produces

73 the drug in packing polymorphic form I, which is the most stable form at room temperature

$74 \quad 22$. To date, form I has been confirmed for all manufactured batches of micronized DPV

75 used in clinical development ${ }^{22}$.

76

77 DPV form I undergoes a solid-solid transition to form II at $\sim 100{ }^{\circ} \mathrm{C}$ (Figure 2; can range

78 from 96.9 to $110.3{ }^{\circ} \mathrm{C}$ ), as evidenced by a small endothermic transition in the differential

79 scanning calorimetry (DSC) trace..$^{20,23,26}$ The variation in solid-solid transition temperature 
80 between form I and form II has been observed for different lots of form I; however, it could 81 not be attributed to a single phenomenon. Upon further heating, DPV form II undergoes 82 crystalline melting at $\sim 220{ }^{\circ} \mathrm{C}$ (ranges from 217.9 to $226.9{ }^{\circ} \mathrm{C}$ ), and then, upon cooling

83 below $100{ }^{\circ} \mathrm{C}$, form II instantaneously reverts to form I. Form I and form II are therefore 84 related enantiotropically with a transition temperature close to $100{ }^{\circ} \mathrm{C}$. The same 85 polymorphic interconversion and crystalline melt transitions are also observed when DPV 86 is incorporated into the silicone elastomer matrix of the Dapivirine Ring-004, indicating 87 that there are no significant drug-polymer interactions. ${ }^{23}$

89 During development, DPV has also been observed in crystalline polymorphic form IV, 90 which is stable at room temperature and forms when dapivirine is recrystallized from 91 methanol at higher temperatures (Figure 1). Upon heating, it exhibits two endothermic 92 transitions at 212 and $221{ }^{\circ} \mathrm{C}$ corresponding to transformation of form IV to form II and 93 crystalline melting of form II, respectively (Figure 1).

95 In order to meet the requirements of the regulatory agencies, it is important to assess how 96 polymorphism affects drug product performance. Surprisingly, this issue seems not to have

97 been reported - at least in the scientific literature - for other vaginal ring products, despite 98 an explicit understanding that different polymorphic forms of a drug can exhibit 99 significantly different solubilities in the polymeric matrix and potentially result in different 100 drug permeation rates. Since forms I and IV are the only DPV polymorphs stable at room 101 temperature (which is the desired storage temperature of the vaginal ring product), this 
102 study was conducted to evaluate the thermal properties and in vitro performance of vaginal

103 rings containing $25 \mathrm{mg}$ DPV as either the form I or the form IV polymorph.

104

105 2. Materials and methods

106 2.1. Materials

107 Non-micronized DPV form I and form IV and micronized form I were supplied by S.A. 108 Ajinomoto OmniChem n.v. (Wetteren, Belgium). DPV form IV was micronized by 109 JetPharma (Balerna, Switzerland). MED-4870 addition-cure silicone elastomer (Parts A 110 and B) and MED-360 silicone oil were purchased from NuSil Technology (Carpinteria, 111 CA, USA). Potassium dihydrogen orthophosphate, potassium hydroxide and urea (AnalaR, 112 analytical reagent grade) were purchased from VWR International Ltd. (Dublin, Ireland). 113 Norethindrone was purchased from LGM Pharma, (Nashville, TN, USA). HPLC-grade 2114 propanol (IPA) and acetonitrile, phosphoric acid ( $85 \% \mathrm{w} / \mathrm{w}$ in water), Tween 80 , sodium 115 chloride, calcium hydroxide, bovine serum albumin, lactic acid, acetic acid and glucose 116 were all purchased from Sigma-Aldrich (Gillingham, UK). A Millipore Direct-Q 3 UV 117 Ultrapure Water System (Watford, UK) was used to obtain HPLC-grade water. Simulated 118 vaginal fluid $+0.2 \%(\mathrm{w} / \mathrm{v})$ Tween $80(\mathrm{SVF}+\mathrm{Tw}$ ween) release media was prepared according 119 to a previously described method followed by addition of the Tween 80 component. $^{43}$

\section{$121 \quad 2.2$ Thermal analysis}

122 The thermal stability of DPV forms I and IV were analysed by thermogravimetric analysis 123 (TGA) using a TA Instruments Q50 ${ }^{\mathrm{TM}}$ Thermogravimetric Analyser and a TA Instruments 124 Differential Scanning Calorimeter Q20 ${ }^{\mathrm{TM}}$ (TA Instruments, UK). For these experiments, 
$1255-10 \mathrm{mg}$ of sample was heated from 25 to $300^{\circ} \mathrm{C}$ at $10^{\circ} \mathrm{C} / \mathrm{min}$ in an open aluminium pan

126 under a nitrogen atmosphere. For differential scanning calorimetry (DSC) experiments, 5-

$1277 \mathrm{mg}$ of sample (either pure polymorph or $10 \% \mathrm{w} / \mathrm{w}$ DPV-loaded silicone elastomer)

128 underwent heat-cool-heat cycles between 20 and $235^{\circ} \mathrm{C}$ using a heating rate of $10{ }^{\circ} \mathrm{C}$ per

$129 \mathrm{~min}$. The temperature range was selected to encompass the molding temperatures

130 commonly used to fabricate DPV matrix-type rings via injection molding processes (160-

$\left.131180{ }^{\circ} \mathrm{C}\right)$. For each sample, onset temperature $\left({ }^{\circ} \mathrm{C}\right)$, peak temperature $\left({ }^{\circ} \mathrm{C}\right)$ and enthalpy

$132(\Delta \mathrm{H}, \mathrm{J} / \mathrm{g})$ values were recorded for each thermal transition observed.

\section{$134 \quad$ 2.3. Particle size analysis}

135 The particle size distributions (PSDs) of micronized and non-micronized forms of both 136 polymorphs were characterised using a Mastersizer 3000 (Malvern, UK) instrument fitted 137 with an AERO S accessory. Approximately $1 \mathrm{~g}$ of material was weighed and added to the 138 Venturi. Using an air pressure of $2 \operatorname{Bar}(\mathrm{g})$, the hopper gap was sequentially raised in 0.5 $139 \mathrm{~mm}$ steps from $0.5 \mathrm{~mm}$ and the feed rate increased to between 30 and $60 \%$ to provide a 140 reasonable flow of powder into the instrument. The target obscuration range was $1-4 \%$. A 141 minimum of six measurements of each sample were performed to give an estimate of the 142 variability about the measurement.

\section{2.4. Powder X-ray diffraction}

145 Powder X-ray diffraction (PXRD) patterns of non-micronized and micronized DPV form 146 I and IV powders were obtained using a X'PERT Pro MPR X-ray diffractometer 147 (PANalytical Ltd., UK). Samples were pressed onto a zero background holder so that a 
148 smooth, flat surface was achieved and mounted in a rotating sample holder. Samples were

149 exposed to $\mathrm{CuK} \alpha$ radiation $(40 \mathrm{kV}, 40 \mathrm{~mA})$, scanned in continuous mode across the $2 \theta$

150 angular range of $3.0-90.0^{\circ}$ with a step size of $0.016^{\circ}$.

152 2.5. Microscopy analysis

153 Digital microscopy was performed using a Keyence VHX-700F series Digital Microscope

154 (Keyence Limited, UK) fitted with an RZ 20-200x wide-range zoom lens. A small sample 155 was dusted onto a section of adhesive tape to provide a thin layer of powder for particle 156 morphology (shape and size) evaluation.

\section{2.6. Ring manufacture}

159 Matrix-type vaginal rings containing $25 \mathrm{mg}$ micronized and non-micronized DPV form I 160 or form IV dispersed in MED-4870 silicone elastomer were manufactured using a 161 Babyplast ${ }^{\mathrm{TM}}$ 6/10P injection molding machine (Chronoplast, Spain). DPV MED-4870 Part 162 A premixes (100 g) were prepared by accurately weighing appropriate quantities of MED$1634870(97.5 \% \mathrm{w} / \mathrm{w})$, MED-360 silicone oil $(2.1875 \% \mathrm{w} / \mathrm{w})$ and DPV $(0.3125 \% \mathrm{w} / \mathrm{w})$ into a 164 sealed polypropylene container before mixing at $3000 \mathrm{rpm}$ for $3 \mathrm{~min}$ in a DAC-150 FVZ165 K Speedmixer ${ }^{\mathrm{TM}}$ (Hauschild, Germany). Part B premixes were manufactured using the 166 same protocol. Four $100 \mathrm{~g}$ portions of premix A and premix B were prepared (800 $\mathrm{g}$ in 167 total) for each DPV polymorph formulation. Premixes were stored at $4{ }^{\circ} \mathrm{C}$ until use. 168 Immediately prior to injection molding, $\sim 100 \mathrm{~g}$ portions each of Part A premix and Part B 169 premix were sequentially added to a large plastic Speedmixer ${ }^{\mathrm{TM}}$ container until $\sim 400 \mathrm{~g}$ in 170 total had been transferred. The material was handmixed for $30 \mathrm{~s}$, speedmixed at $2350 \mathrm{rpm}$ 
171 for $30 \mathrm{~s}$ and further speedmixed for $60 \mathrm{~s}$ at $1800 \mathrm{rpm}$. The silicone elastomer mix was

172 transferred to a Babyplast ${ }^{\mathrm{TM}}$ cartridge which was then fitted into the Babyplast ${ }^{\mathrm{TM}}$ injection

173 molding machine. Rings were manufactured at $185^{\circ} \mathrm{C}$ for $60 \mathrm{~s}$.

174

\section{$175 \quad$ 2.7. Ring appearance and weight}

176 Ring weight, colour, external diameter $(\mathrm{ExD})$ and cross-sectional diameter (CSD) were

177 recorded in order to assess the consistency of ring physical parameters. Ten rings from 178 each DPV polymorph formulation were randomly selected and evaluated. CSD and ExD 179 were measured using digital callipers (RS Components, UK). Care was taken not to 180 compress the ring during measurement.

\section{2.8. Mechanical testing}

183 In the absence of a ratified international standard on the mechanical testing of vaginal rings, 184 the Food and Drug Administration's (FDA) Center for Drug Evaluation and Research 185 (CDER) have published nonbinding recommendations to industry in respect of tests for 186 vaginal microbicide drug product specification, which include the mechanical testing of

187 ring devices. ${ }^{44}$ Here, as part of ongoing efforts to establish practical test methods, we have 188 applied mechanical test methods to vaginal rings based on the minimum requirements and 189 test methods used for reusable silicone rubber contraceptive diaphragms, as described in 190 ISO-8009:2014.

192 Shore A Hardness testing, also known as durometer testing, was performed on five rings 193 randomly selected from each DPV polymorph production run. Measurement was carried 
194 out using a Sauter HBA 100-0 graduated dial durometer (Sauter, Switzerland) calibrated

195 for Shore A hardness (arbitrary units). During testing the rings were placed on an

196 unyielding, flat surface. With the durometer held in a vertical position, the instrument's

197 indentor was pressed on the uppermost surface of the ring in a constant movement without

198 shocks until the presser foot was parallel to the ring surface. The maximum deflection on

199 the dial (0-100), representing the Shore Hardness was recorded. Four individual

200 measurements per ring were recorded.

201

202 Compression testing was performed using a TA.XTplus Texture Analyser (Stable

203 Microsystems, UK). Rings previously selected for non-destructive durometer testing were

204 placed in the appropriate holder and analysed in compression mode using a test speed of 2

$205 \mathrm{~mm} / \mathrm{s}$ and a target distance of $5.0 \mathrm{~mm}$. Six compression cycles were performed, and the

206 last five values for the maximum compressive force exerted by the texture analyser

207 recorded. The first value is not recorded to allow the ring to stabilize in the holder during

208 the first compression cycle.

209

210 Tensile strength testing was also performed using the TA.XTplus Texture Analyser. Rings

211 were placed around upper and lower tensile grips and analysed in tension mode with a test

212 speed of $10 \mathrm{~mm} / \mathrm{s}$ and a target force of $5 \mathrm{~kg}$. The pass/fail criterion for tensile strength

213 testing was set at $5 \mathrm{~kg}$ i.e. if the ring withstood a force equivalent to $5 \mathrm{~kg}$ without rupture

214 then it was deemed acceptable.

215

216 2.9. In vitro release testing 
217 Twenty-four samples of each ring formulation were selected for in vitro release testing

218 over a 30-day period - twelve rings for release into a 1:1 mixture of IPA $+\mathrm{H}_{2} \mathrm{O}$ and twelve

219 for release into SVF+Tween. Both media have been used routinely for in vitro release

220 testing of silicone elastomer vaginal rings, and other vaginal formulations, containing

221 highly lipophilic poorly water-soluble antiretroviral microbicides, including

222 DPV. . $^{17,19,20,23,25,26,31,45-47}$. IPA/water is commonly used as a performance test to predict and 223 monitor the consistency in manufacturing. SVF is intended to mimic the chemical

224 composition of vaginal fluid, including $\mathrm{pH}$ and osmolarity matched to normal vaginal

225 fluid. ${ }^{43}$ However, solubility of DPV in SVF is impractically low $(<1 \mu \mathrm{g} / \mathrm{mL}),{ }^{22,46}$ and, as

226 a result, in vitro release from vaginal rings into this medium does not correlate with in vivo

227 release (as measured by residual drug content following clinical use). By comparison, use

228 of SVF $+0.2 \% \mathrm{w} / \mathrm{v}$ Tween 80 closely mimics in vivo release, ${ }^{27,48}$ and its use has been

229 supported by regulatory authorities.

230

231 On Day 0, each ring was placed into a $250 \mathrm{~mL}$ glass, screw-top bottle containing $200 \mathrm{~mL}$

232 of either IPA $+\mathrm{H}_{2} \mathrm{O}$ or $\mathrm{SVF}+\mathrm{Tween}$ release medium and stored in a temperature-controlled

233 orbital shaking incubator $\left(37^{\circ} \mathrm{C}, 60 \mathrm{rpm}, 25 \mathrm{~mm}\right.$ orbital throw). The release medium was

234 sampled and completely replaced $(100 \mathrm{~mL})$ daily, with the exception of weekends where

$235200 \mathrm{~mL}$ was added. Drug release was quantified by reverse-phase HPLC with UV detection

236 (Section 2.11).

237

\section{2.10. Content assay and residual content testing}


239 Both the total DPV content of manufactured rings and the residual content of rings after in

240 vitro release testing were assessed ( $\mathrm{n}=6$ per formulation per test). Rings were weighed and

241 then cut in half along the length of the ring. The ring halves were immediately transferred

242 into individually labelled $250 \mathrm{~mL}$ glass flasks containing $100 \mathrm{~mL}$ acetone. Flasks were

243 sealed and placed in a temperature-controlled orbital shaking incubator $\left(37^{\circ} \mathrm{C}, 60 \mathrm{rpm}, 25\right.$

$244 \mathrm{~mm}$ orbital throw). After $24 \mathrm{~h}$, the flasks were removed and allowed to cool to room

245 temperature. A $1.00 \mathrm{~mL}$ aliquot of the acetone extraction solution was transferred to a 100

$246 \mathrm{~mL}$ volumetric flask using a positive displacement pipette and diluted to volume with

247 methanol. Samples were allowed to stand at ambient temperature for $1 \mathrm{~h}$ before final

248 dilution to volume with methanol. Samples were transferred to HPLC vials and analysed

249 against standard solutions of known DPV concentration. 


\subsection{Solubility determination}

251 Thermodynamic solubility of DPV (form 1 and form IV, micronised and non-micronised)

252 was measured using the shake-flask method at $37^{\circ} \mathrm{C}$ in both $\mathrm{SVF}+0.2 \% \mathrm{w} / \mathrm{w}$ Tween and

$2531: 1 \mathrm{v} / \mathrm{v} \mathrm{IPA} /$ water mixture. For SVF/Tween measurement, $\sim 5 \mathrm{mg}$ DPV was added to a

254 glass vial followed by $5.00 \mathrm{~mL} \mathrm{SVF/Tween;} \mathrm{for} \mathrm{IPA/water} \mathrm{measurement,} 40 \mathrm{mg}$ DPV

255 was added to a glass vial followed by $5.00 \mathrm{~mL}$ IPA/water. The sealed vials were placed in

256 an orbital shaking incubator for $72 \mathrm{hr}$. While still in the incubator but with shaking stopped,

$2571.00 \mathrm{~mL}$ and $100 \mu \mathrm{L}$ volumes of the saturated SVF/Tween and IPA/water solutions,

258 respectively, were sampled from the vials using suitable micropipettes and placed in new

259 glass vials, taking care not to sample the settled excess solid drug layer at the bottom of

260 each vial. SVF/Tween samples were subsequently diluted twofold for HPLC analysis,

261 while IPA/water samples were diluted by a factor of 100. Drug concentrations were

262 subsequently quantified by HPLC. In a similar fashion, the solubilities of both DPV form

2631 and form IV (micronized only) were measured in aqueous media at different $\mathrm{pH}$ values

$264-0.1 \mathrm{M} \mathrm{HCl}, 0.01 \mathrm{M} \mathrm{HCl}, \mathrm{pH} 2(\mathrm{KCl} / \mathrm{HCl}), \mathrm{pH} 4$ (acetate buffer), $\mathrm{pH} 6$ (phosphate buffer),

265 pH8 (phosphate buffer). For each solubility measurement, the residual solids were analyzed

266 by PXRD to determine the extent of form conversion during the solubility analysis and to

267 ensure the results reflect the true solubility of each form.

268

\section{2.12. HPLC Analysis}


270 Samples for DPV content analysis in rings were analysed on a Waters HPLC system

271 (Waters Corporation, Dublin, Ireland) consisting of a 1525 Binary HPLC pump with an in-

272 line degasser AF unit, 1500 column heater, 717 Plus Autosampler and a 2487 dual

273 wavelength absorbance detector. $10 \mu \mathrm{L}$ of each content sample was injected onto a

274 Kromasil C18 HPLC column ( $150 \mathrm{~mm} \times 4.6 \mathrm{~mm}, 5 \mu \mathrm{m}$ particle size). Column temperature

275 was maintained at $25^{\circ} \mathrm{C}$ and isocratic elution was performed using a mobile phase of $75 \%$

276 HPLC-grade methanol and $25 \%$ water with a flow rate of $0.75 \mathrm{~mL} / \mathrm{min}$ and a run time of

$27715 \mathrm{~min}$. DPV was detected at $257 \mathrm{~nm}$ after approximately $10.8 \mathrm{~min}$.

278

279 In vitro release samples $(25 \mu \mathrm{L})$ were injected onto a Thermo Scientific BDS Hypersil ${ }^{\mathrm{TM}}$

280 C18 HPLC column ( $150 \mathrm{~mm} \times 4.6 \mathrm{~mm}, 3 \mu \mathrm{m}$ particle size) fitted with a guard column. The 281 column was held at $45{ }^{\circ} \mathrm{C}$ and isocratic elution was performed using a mobile phase of $45 \%$

282 HPLC-grade acetonitrile and 55\% phosphate buffer $(\mathrm{pH} 3.0 ; 7.7 \mathrm{mM})$ with a run time of 8 $283 \mathrm{~min}$. DPV was detected at $240 \mathrm{~nm}$ after $6.1 \mathrm{~min}$. 


\subsection{Statistical analyses}

286 Where appropriate, data sets were analysed using a one-way ANOVA followed by post287 hoc analysis using the Tukey-Kramer multiple comparisons test. Analysis was conducted 288 using GraphPad Prism software and significance was noted for a P value of less than 0.05: $289 *$ significant $(0.01<\mathrm{P}<0.05), * *=$ very significant $(0.001<\mathrm{P}<0.01), * * *=$ extremely 290 significant $(\mathrm{P}<0.001), \mathrm{ns}=$ not significant $(\mathrm{P}>0.05)$

292 The similarity factor $\left(f_{2}\right)$ - a logarithmic reciprocal square root transformation of one plus 293 the mean squared (the average sum of squares) differences of drug percent dissolved 294 between the test and the reference products - was calculated for ring dissolution data using 295 Equation 1. ${ }^{49,50}$ The similarity factor fits the result between 0 and 100. It is 100 when the 296 test and reference profiles are identical and tends to 0 as the dissimilarity increases. FDA 297 and EMEA recommend that two dissolution profiles are similar when $f_{2}$ has a value 298 between 50 and 100 following testing of at least 12 individual dosage units.

\section{Equation 1.}

$$
f_{2}=50 \times \log \left(\left[1+\frac{1}{n} \sum_{j=1}^{n}\left|R_{j}-T_{j}\right|^{2}\right]^{-0.5} \times 100\right)
$$




\section{3. Results and Discussion}

\subsection{Thermal analysis}

302 DPV form I and form IV polymorphs were initially tested using TGA to establish their 303 thermal stability over the range of temperatures encountered during ring manufacture via 304 injection molding. Both polymorphs were stable up to temperatures around $240{ }^{\circ} \mathrm{C}$, with 305 total percent weight loss less than $0.5 \%$ at $240{ }^{\circ} \mathrm{C}$ for both polymorphic forms (data not 306 shown). The polymorphs were then examined by DSC using a heat-cool-heat cycle 307 between 20 and $235^{\circ} \mathrm{C}$. Representative thermograms for the non-micronized forms of DPV 308 form I and form IV are presented in Figure 2A and 2B, respectively. Table 1 displays the 309 mean onset peak temperature $\left({ }^{\circ} \mathrm{C}\right)$, the peak maximum temperature $\left({ }^{\circ} \mathrm{C}\right)$ and the enthalpy $310(\mathrm{~J} / \mathrm{g})$ for each transition recorded in the thermograms.

312 Non-micronized DPV form I, the most stable polymorphic form of the compound at room

313 temperature and the form produced in the synthesis of DPV, displayed characteristic 314 melting endotherms at $101^{\circ} \mathrm{C}$ and $220^{\circ} \mathrm{C}$ during the first heat cycle (Figure 2A), attributed 315 to the solid-solid I $\rightarrow$ II polymorphic transformation and the form II crystalline melt, 316 respectively..$^{20,22,23}$ Upon cooling of this melt, an endothermic step-like shift associated 317 with formation of amorphous DPV was observed around $80^{\circ} \mathrm{C}$. The second heat cycle then 318 showed a glass transition $\left(\mathrm{T}_{\mathrm{g}}\right)$ with amorphous relaxation close to $80{ }^{\circ} \mathrm{C}$, followed by an 319 exothermic recrystallization transition at $163{ }^{\circ} \mathrm{C}$ and the form II melt endotherm at $220{ }^{\circ} \mathrm{C}$.

320 Similar thermal behaviour was observed for micronized DPV form I (DSC trace not shown, 321 but data presented in Table 1). 
323 By comparison, the non-micronized DPV form IV showed two sharp melting endotherm

324 transitions, one at $206^{\circ} \mathrm{C}$ attributed to the solid-solid IV $\rightarrow$ II transition and the other at 220

$325{ }^{\circ} \mathrm{C}$ due to crystalline melting of form II (Figure 2B). Micronized DPV form IV displayed

326 a broader and smaller IV $\rightarrow$ II endothermic transition at $\sim 190^{\circ} \mathrm{C}$ compared to that observed

327 for the non-micronized form IV material (DSC trace not shown, but data presented in Table

328 1), attributed to the smaller particle size of the micronized material and/or changes in 329 crystallinity induced during the micronization process.

330

331 3.2. Particle size distribution

332 The PSDs of DPV form I and form II polymorphs are presented in Figure 3 for both non333 micronized (nm) and micronized (m) material. The distributions were unimodal (modal 334 particle diameters for forms $\mathrm{I}_{(\mathrm{nm})}, \mathrm{IV}_{(\mathrm{nm})}, \mathrm{I}_{(\mathrm{m})}$ and $\mathrm{IV}_{(\mathrm{m})}$ were $163,76,5.9$ and $5.2 \mu \mathrm{m}$, 335 respectively), except for an additional second smaller peak at $67 \mu \mathrm{m}$ for the form $\mathrm{I}_{(\mathrm{m})}$ 336 material. A summary of the $\mathrm{d}_{90}, \mathrm{~d}_{50}$ and $\mathrm{d}_{10}$ values are presented in Table 2 alongside values 337 quoted in supplied certificates of analysis (where available). The data in Table 2 indicates

338 that the experimentally determined PSD values for non-micronized DPV form I were 339 slightly larger than the values stated in the certificate of analysis, which may be due to 340 slight differences in the method of analysis or powder sampling protocols. In particular, 341 for larger particle size materials, sampling protocols can have a greater influence on the 342 measured value. After micronization, the particle size distributions for both polymorphs 343 were similar, with an overall tendency towards slightly smaller particles observed for the 344 form IV sample, as evidenced both by the overlap of the distributions (Figure 3B) and the 345 similarity of the values for $\mathrm{d}_{90}, \mathrm{~d}_{50}$ and $\mathrm{d}_{10}$ (Table 2 ). The other experimentally determined 
346 particle size distribution values were in good agreement with those specified on the

347 certificates of analysis.

\section{3.3. Powder X-ray diffraction}

350 The X-ray diffraction traces for non-micronized and micronized DPV form I and form IV 351 materials are presented in Figure 4. Both DPV polymorphs are characterised by sharp 352 diffraction peaks confirming the highly crystalline nature of the materials. No significant 353 amorphous content was observed as indicated by the absence of broad peaks and halos.

354 Comparison of traces obtained for the non-micronized and micronized forms of the same 355 polymorph demonstrate a high degree of similarity with regard to peak positions, indicating 356 that the micronization process does not significantly alter the crystal form of either 357 polymorph. However, minor differences in peak intensities were observed, and may be due 358 to a combination of factors including the particle (crystallite) size, orientation of the 359 crystals (preferred or random), amount of powder applied to the background sample holder, 360 or differences in powder packing within the sample holder. Both the non-micronized 361 (Figure 4A) and micronized (Figure 4B) DPV form I diffraction patterns showed 362 significant differences in diffraction peak positions when compared to the form IV 363 materials. In particular, DPV form I traces exhibited distinct diffraction peaks at $2 \theta=5.2^{\circ}$ 364 and $10.3^{\circ}$ not present in the form IV diffraction patterns. 
367 Representative micrographs of micronized and non-micronized crystals of DPV form I and

368 IV are presented in Figure 5. The non-micronized materials showed large and highly 369 crystalline primary particles in the range of 50-350 $\mu \mathrm{m}$ (Figures 5A and 5B). DPV form

370 IV has a higher proportion of smaller crystals in the $<100 \mu \mathrm{m}$ range compared to DPV form

371 I, as confirmed by particle size distribution analysis (Figure 3 ). The micrographs of the 372 micronized DPV materials displayed particles significantly smaller in size (mostly $<10$

$373 \mu \mathrm{m})$. Although the majority of the micronized material was present as small primary

374 particles, some larger agglomerations of particles were also visible.

$376 \quad 3.5$. Ring appearance and weight

377 All manufactured rings were free from visible foreign matter and had an off-white opaque 378 appearance consistent with uniform distribution of the white DPV powder throughout the 379 otherwise transparent silicone elastomer matrix. Mean ring weight, ExD and CSD for each 380 form I and form IV ring manufacturing batch ( $\mathrm{n}=5$ per batch) are recorded in Table 3 . All 381 rings had weights $\sim 8.0 \mathrm{~g}$, CSDs $\sim 7.6 \mathrm{~mm}$ and ExDs $\sim 56.4 \mathrm{~mm}$.

\section{3.6. Mechanical Testing}

384 Shore A Hardness measurements, recorded for sample rings from each manufacturing 385 batch and presented in Table 4, are close to 65 . The product profile for MED-4870 states a 386 Shore A Hardness value of 70 for samples cured at $165^{\circ} \mathrm{C}$ (ASTM D2240). The differences 387 observed here are attributed to differences in the cure time temperature profile and the other 388 ingredients included in the formulation, which can have an effect on the mechanical 
performance of the silicone elastomer. Although Shore A hardness measurement is

390 commonly used in the rubber industry as a standard indicator of mechanical performance,

391 it is regarded as a basic test and can provide only limited information regarding changes to

392 the mechanical properties of the rings. Since the ring surface is curved, the test performed

393 does not conform to ASTM D2240 or ISO 868:2003 testing standards for shore hardness,

394 which require test specimens to have a flat surface and be at least $6 \mathrm{~mm}(1 / 4$ in) thick.

396 Compression testing to measure the maximum force required to compress a ring a distance 397 of $5 \mathrm{~mm}$ vertically was also performed for each ring formulation batch $(\mathrm{n}=5)$. The results, 398 presented in Figure 6, show that the mean maximum force required for compression of the $399 \mathrm{DPV}_{(\mathrm{m})}$ form I and form IV rings was similar for all manufacturing batches. No significant 400 batch-to-batch variability between rings of the same formulation was observed. Statistical 401 analysis confirmed that all ring batches tested had statistically similar mechanical 402 properties.

404 Tensile strength analysis was performed to assess the integrity of the rings on application 405 of a force equivalent to $5 \mathrm{~kg}$. Ten rings of each formulation were analysed. All rings were 406 able to withstand a force equivalent to $5 \mathrm{~kg}$ without rupture (data not shown). This arbitrary $4075 \mathrm{~kg}$ value has been used in the testing of other vaginal ring products (unpublished data). 408 In clinical use, however, vaginal ring devices are not likely to undergo extensive tensile 409 deformation. Therefore, the test is primarily used as a quality performance measure for 410 comparison of different ring formulations and manufacturing processes. 
413 Mean daily and cumulative release versus time plots for both DPV forms I and IV from 414 matrix-type vaginal rings into IPA $+\mathrm{H}_{2} \mathrm{O}$ and SVF+Tween media are presented in Figure 7.

415 The declining daily release values with time (Figures $7 \mathrm{~A}$ and $7 \mathrm{~B}$ ) are indicative of $\mathrm{t}^{1 / 2}$ 416 kinetics and typical of permeation-controlled drug delivery systems comprising non417 biodegradable polymers containing excess solid drug within the matrix. ${ }^{20,23,51,52}$ Daily DPV 418 release values were greater for release into IPA $+\mathrm{H}_{2} \mathrm{O}$ compared with SVF+Tween across 419 all time points and for both form I and form IV rings, reflecting the higher solubility of $420 \mathrm{DPV}$ in the solvent/water system. Mean day 1 release values for DPV into IPA $+\mathrm{H}_{2} \mathrm{O}$ were 4212459 and $2564 \mu \mathrm{g}$ for form I and IV rings, respectively, decreasing to 191 and $183 \mu \mathrm{g}$, 422 respectively, on day 30 . Thus, the $\mathrm{d} 1 / \mathrm{d} 30$ release ratios for this release medium were 12.9 423 and 14.0 for form I and IV rings, respectively. Use of SVF+Tween as the release medium 424 produced significantly different ( $\mathrm{p}$-value $<.00001)$ day 1 mean release values for the form 425 I and IV rings (349 and $578 \mu \mathrm{g}$, respectively), while mean day 30 release values were more 426 similar (116 and $106 \mu \mathrm{g}$, respectively; p-value .000019) (Figure 7B); the corresponding $427 \mathrm{~d} 1 / \mathrm{d} 30$ release ratios were 3.0 and 5.5, respectively. It is therefore apparent that the 428 SVF+Tween release medium blunts the day 1 in vitro release value relative to the day 30 429 value, compared with the IPA $+\mathrm{H}_{2} \mathrm{O}$ release medium. In general, greater variability is 430 observed with the SVF+Tween daily release values compared to those measured using 431 IPA $+\mathrm{H}_{2} \mathrm{O}$, reflecting differences in solvating power between the release media.

433 Release rates $\left(\mu \mathrm{g} / \mathrm{day}^{0.5}\right)$ and coefficients of correlation $\left(\mathrm{r}^{2}\right)$ obtained from linear regression 434 analysis of the cumulative DPV release vs. root time plots are presented in Table 5. 
436 Comparing the release between polymorphs reveals that the profiles are similar, with

437 almost identical release into both release media. The only difference of note is increased

438 DPV release over the first three days into SVF+Tween for the form IV polymorph (Figure

439 7B). Since there is no significant difference in SVF+Tween solubility between the

440 polymorphs (Table 6), possible explanations include differences in silicone elastomer

441 solubility between the two forms of DPV, or differences in drug distribution at the surface

442 of the ring devices. Given that much greater variability in drug concentrations are observed

443 in vaginal ring pharmacokinetic studies, ${ }^{28,30,53-55}$ it is highly unlikely that these relatively

444 small differences in in vitro release over early timepoints would be clinically significant.

445 Comparing the line equation gradients of the cumulative release lines highlights the small

446 differences observed in terms of the release between different polymorphs. This was

447 confirmed by calculating the similarity factor $\left(\mathrm{f}_{2}\right)$ which has been recommended by the

448 FDA for dissolution profile comparison. ${ }^{50,56}$ As the mean cumulative DPV release did not

449 exceed $55 \%$ in either case, all of the available release values were included in the

450 calculations. Based on these results, calculated $\mathrm{f}_{2}$ values were 98.5 for release into

$451 \mathrm{IPA}+\mathrm{H}_{2} \mathrm{O}$ and 94.9 for release into $\mathrm{SVF}+$ Tween, both well above the value of 50 often

452 used to indicate similarity. Interestingly, the in vitro cumulative release levels obtained 453 with SVF+Tween over a 30-day period for both the form I and form IV rings were similar

454 to 28-day in vivo release levels observed with IPM's $25 \mathrm{mg}$ DPV matrix ring 004 ( 4

$455 \mathrm{mg}) .^{33,39}$ This indicates that the SVF+Tween release media more closely mimics the 456 amount of drug released in vivo than either SVF alone or the IPA $+\mathrm{H}_{2} \mathrm{O}$ medium. 
459 Initial dapivirine content in the rings post-manufacture was $24.87 \pm 0.16$ and $25.82 \pm 0.28$

$460 \mathrm{mg}$ for rings containing form I and form IV dapivirine, respectively (equivalent to 99.5 and

$461 \quad 103.3 \%$ of the nominal content value), as measured by a solvent extraction method, and

462 highlighting the consistency of the manufacturing process. Following completion of in

463 vitro release testing, all rings were tested for residual dapivirine content. The residual

464 content values were then combined with the cumulative release values and compared to

465 initial ring content values to assess mass balance. The data presented in Table 6

466 demonstrate almost identical cumulative release between the two polymorphs of $13.1 \mathrm{mg}$

467 and $4.5 \mathrm{mg}$ into IPA $+\mathrm{H}_{2} \mathrm{O}$ and $\mathrm{SVF}+$ Tween over 30 days. The amounts of DPV recovered

468 after in vitro release testing are also consistent with the slightly higher initial loading in the

469 rings containing form IV DPV compared to those containing form I. Thus, the calculated

470 initial loadings for each polymorph are higher for form IV at approximately $25.8 \mathrm{mg}$,

471 compared to form I at approximately $25.0 \mathrm{mg}$. These values fit very well with the initially

472 calculated content values of $25.8 \mathrm{mg}$ and $24.9 \mathrm{mg}$ for form IV and form I respectively.

473

474 3.9. DPV solubility

475 DPV, with an experimental pKa value of $5.54,{ }^{46}$ exhibits the typical weak base behaviour 476 of increased solubility as $\mathrm{pH}$ is lowered (Figure 8). Moreover, the solubility vs. pH profiles 477 are very similar for polymorphic forms I and IV, within the limits of experimental error. 478 The lower solubility values at $\mathrm{pH} 1$ are due to the common ion effect (i.e. chloride ions) 479 associated with increased concentration of hydrochloric acid. Based on these in vitro 480 solubility data, DPV solubility at vaginal $\mathrm{pH}$ values typical of women of reproductive age 
481 (typically between 3.5 and 7; the higher values are common with certain vaginal infections

482 and in the presence of semen ${ }^{43,57}$ ) would lie within the range $0-15 \mu \mathrm{g} / \mathrm{mL}$, which goes some

483 way to explaining the wide variation in DPV pharmacokinetics measured in women during

484 ring use. ${ }^{14,28,53-55}$

485

486 Experimentally determined values of thermodynamic solubility for DPV forms I and IV -

487 micronised and non-micronised materials, and measured in both 1:1 v/v IPA/water and

$488 \mathrm{SVF}+0.2 \% \mathrm{w} / \mathrm{v}$ Tween 80 - are presented in Table 8. As expected, DPV solubility in

$489 \mathrm{IPA} /$ water $(\sim 1200 \mu \mathrm{g} / \mathrm{mL})$ is significantly greater (by a factor of $\sim 75)$ compared with

490 solubility measured in SVF/Tween $(\sim 16 \mu \mathrm{g} / \mathrm{mL})$. That in vitro DPV release from vaginal

491 rings into these two release media does not differ by a similar factor is a consequence of

492 the permeation-controlled release kinetics that apply to silicone elastomer vaginal rings,

493 wherein molecular diffusion of drug through the silicone matrix is rate controlling. ${ }^{51}$ The

494 data also clearly illustrate that neither DPV particle size nor the polymorphic form of DPV

495 influence the thermodynamic solubility value, irrespective of the release medium tested.

496 PXRD analysis of the residual DPV material after preparation of saturated solutions

497 confirmed the no form conversion was observed during the solubility analysis and

498 indicating that the results reflect the true solubility of each form (Table 8).

499

\section{4. Conclusions}

501 This is the first report of the impact of drug polymorphism on the performance 502 characteristics of a vaginal ring device. DPV form I and form IV polymorphs were 503 distinguished using DSC, PXRD and solubility analyses. TGA demonstrated that both 
504 polymorphs were thermally stable over the range of processing temperatures likely to be 505 encountered during manufacture. Particle size analysis revealed a similar size distribution 506 for micronized versions of both polymorphs whereas the non-micronized form I average 507 particle size was slightly larger than form IV. Manufacture of silicone elastomer rings 508 nominally containing $25 \mathrm{mg}$ DPV produced rings with a mean content with $5 \%$ of the 509 nominal value for both polymorphs. In vitro release testing of rings showed a very similar 510 release profile for both polymorphs with similarity factor $f_{2}$ values greater than 90 . An 511 increase in the day 1 to day 3 release for the form IV polymorph compared to the form I 512 polymorph was observed. Possible explanations for this difference include variations in 513 dissolution rates between the two polymorphs and or different surface distributions from 514 manufacture. DPV mass balance was achieved from residual content values plus the 515 cumulative release values recorded into each media. Release of DPV into SVF+Tween 516 over 30 days more closely matches the amount of DPV released in vivo over a similar time 517 period than either IPA $+\mathrm{H}_{2} \mathrm{O}$ or SVF only. Finally, no significant differences in 518 thermodynamic solubility were observed for the various particle size and polymorphic 519 forms of DPV. 


\section{Acknowledgements}

521 The work was supported by a grant to Queen's University Belfast from the International

522 Partnership for Microbicides, through the generous support from the Ministry of Foreign

523 Affairs of the Netherlands and the American people through the United States Agency for

524 International Development (USAID) through the President's Emergency Plan for AIDS

525 Relief (PEPFAR).

526

527 Declaration of interests

528 All authors declare no any actual or potential conflicts of interest.

529

530 Author contribution to manuscript

531 All authors contributed to the design of the study and drafting of the manuscript for 532 submission. CFM, DJM, PB and KM performed the experimental work. All authors 533 approved submission of the manuscript. 


\section{References}

535 1. Brittain HG. Polymorphism and Solvatomorphism 2010. J Pharm Sci.

$536 \quad$ 2012;101(2):464-484. doi:10.1002/jps.22788.

537 2. Chemburkar SR, Bauer J, Deming K, et al. Dealing with the Impact of Ritonavir 538 Polymorphs on the Late Stages of Bulk Drug Process Development. Org Process 539 Res Dev. 2000;4(5):413-417. doi:10.1021/op000023y.

540 3. Bauer J, Spanton S, Henry R, et al. Ritonavir: An Extraordinary Case of 541 Conformational Polymorphism. Pharm Res. 2001;18(6):859-866.

542 4. FDA. Guidance for Industry ANDAs: Pharmaceutical Solid Polymorphism.

543 Evaluation.

544 /Guidances/ucm072866.pdf. Published 2007. Accessed December 21, 2016.

5. International Conference on Harmonisation. Guidance on Q6A Specifications:

Test Procedures and Acceptance Criteria for New Drug Substances and New Drug Products: Chemical Substances. http://www.ich.org/fileadmin/Public_Web_Site/ICH_Products/Guidelines/Quality/ Q6A/Step4/Q6Astep4.pdf. Published 1999. Accessed December 21, 2016.

6. FDA. Draft Guidance on Specifications: Test Procedures and Acceptance Criteria for New Drug Substances and new Drug Products: Chemical Substances. http://www.fda.gov/Drugs/GuidanceComplianceRegulatoryInformation/Guidances /ucm134966.htm. Published 2000. Accessed December 21, 2016.

7. das Neves J, Martins JP, Sarmento B. Will dapivirine redeem the promises of antiHIV microbicides? Overview of product design and clinical testing. Adv Drug Deliv Rev. 2016;103:20-32. doi:10.1016/j.addr.2015.12.015.

8. D'Cruz OJ, Uckun FM, Cruz OJD, Uckun FM. Dawn of non-nucleoside inhibitorbased anti-HIV microbicides. J Antimicrob Chemother. 2006;57(3):411-423. doi:10.1093/jac/dki464.

9. Di Fabio S, Van Roey J, Giannini G, et al. Inhibition of vaginal transmission of HIV-1 in hu-SCID mice by the non-nucleoside reverse transcriptase inhibitor TMC120 in a gel formulation. AIDS. 2003;17(11):1597-1604. doi:10.1097/01.aids.0000072663.21517.63.

10. Fletcher P, Harman S, Azijn H, et al. Inhibition of human immunodeficiency virus type 1 infection by the candidate microbicide dapivirine, a nonnucleoside reverse transcriptase inhibitor. Antimicrob Agents Chemother. 2009;53(2):487-495. doi:10.1128/AAC.01156-08.

11. Van Herrewege Y, Michiels J, Van Roey J, et al. In vitro evaluation of nonnucleoside reverse transcriptase inhibitors UC-781 and TMC120-R147681 as human immunodeficiency virus microbicides. Antimicrob Agents Chemother. 2004;48(1):337-339. doi:10.1128/AAC.48.1.337.

12. Van Herrewege Y, Vanham G, Michiels J, et al. A series of diaryltriazines and 
diarylpyrimidines are highly potent nonnucleoside reverse transcriptase inhibitors with possible applications as microbicides. Antimicrob Agents Chemother. 2004;48(10):3684-3689. doi:10.1128/AAC.48.10.3684-3689.2004.

13. Akil A, Parniak MA, Cost MR, et al. Development and Characterization of a Vaginal Film Containing Dapivirine, a Non- nucleoside Reverse Transcriptase Inhibitor (NNRTI), for prevention of HIV-1 sexual transmission. Drug Deliv Transl Res. 2011;1(3):209-222. doi:10.1007/s13346-011-0022-6.

14. Nel AM, Coplan P, Smythe SC, et al. Pharmacokinetic assessment of dapivirine vaginal microbicide gel in healthy, HIV-negative women. AIDS Res Hum Retroviruses. 2010;26(11):1181-1190. doi:10.1089/aid.2009.0227.

15. Nel AM, Smythe SC, Habibi S, Kaptur PE, Romano JW. Pharmacokinetics of 2 dapivirine vaginal microbicide gels and their safety vs. Hydroxyethyl cellulosebased universal placebo gel. J Acquir Immune Defic Syndr. 2010;55(2):161-169. doi:10.1097/QAI.0b013e3181e3293a.

16. Major I, Boyd P, Kilbourne-brook M, Saxon G, Cohen J, Malcolm RK. A modified SILCS contraceptive diaphragm for long-term controlled release of the HIV microbicide dapivirine. Contraception. 2013;88(1):58-66. doi:10.1016/j.contraception.2012.10.018.

17. Woolfson AD, Umrethia ML, Kett VL, Malcolm RK. Freeze-dried, mucoadhesive system for vaginal delivery of the HIV microbicide, dapivirine: optimisation by an artificial neural network. Int J Pharm. 2010;388(1-2):136-143. doi:10.1016/j.ijpharm.2009.12.042.

18. das Neves J, Araújo F, Andrade F, Amiji M, Bahia MF, Sarmento B. Biodistribution and Pharmacokinetics of Dapivirine-Loaded Nanoparticles after Vaginal Delivery in Mice. Pharm Res. January 2014. doi:10.1007/s11095-0131287-x.

19. Malcolm RK, Woolfson AD, Toner CF, Morrow RJ, Mccullagh SD. Long-term, controlled release of the HIV microbicide TMC120 from silicone elastomer vaginal rings. J Antimicrob Chemother. 2005;56(5):954-956. doi:10.1093/jac/dki326.

20. Boyd P, Fetherston SM, Mccoy CF, et al. Matrix and reservoir-type multipurpose vaginal rings for controlled release of dapivirine and levonorgestrel. Int J Pharm. 2016;511(1):619-629. doi:10.1016/j.ijpharm.2016.07.051.

21. Nel A, Kapiga S, Bekker L-G, Devlin B, Borremans M, Rosenberg Z. Safety and Efficacy of Dapivirine Vaginal Ring for HIV-1 Prevention in African Women. In: Conference on Retroviruses and Opportunistic Infections. Boston; 2016:110LB.

22. Devlin B, Nuttall J, Wilder S, Woodsong C, Rosenberg Z. Development of dapivirine vaginal ring for HIV prevention. Antiviral Res. 2013;100 Suppl(SUPPL.):S3-8. doi:10.1016/j.antiviral.2013.09.025.

23. Fetherston SM, Boyd P, McCoy CF, et al. A silicone elastomer vaginal ring for HIV prevention containing two microbicides with different mechanisms of action. Eur J Pharm Sci. 2013;48(3):406-415. doi:10.1016/j.ejps.2012.12.002. 
24. Malcolm RK, Boyd PJ, McCoy CF, Murphy DJ. Microbicide vaginal rings: Technological challenges and clinical development. Adv Drug Deliv Rev. 2015;103:33-56. doi:10.1016/j.addr.2016.01.015.

25. Murphy DJ, Desjardins D, Dereuddre-Bosquet N, et al. Pre-clinical development of a combination microbicide vaginal ring containing dapivirine and darunavir. $J$ Antimicrob Chemother. 2014;(i):1-12. doi:10.1093/jac/dku160.

26. Murphy DJ, Boyd P, McCoy CF, et al. Controlling levonorgestrel binding and release in a multi-purpose prevention technology vaginal ring device. $J$ Control Release. 2016;226:138-147. doi:10.1016/j.jconrel.2016.02.020.

27. Baeten JM, Palanee-Phillips T, Brown ER, et al. Use of a Vaginal Ring Containing Dapivirine for HIV-1 Prevention in Women. $N$ Engl J Med. 2016:NEJMoa1506110. doi:10.1056/NEJMoa1506110.

28. Nel A, Smythe S, Young K, et al. Safety and pharmacokinetics of dapivirine delivery from matrix and reservoir intravaginal rings to HIV-negative women. $J$ Acquir Immune Defic Syndr. 2009;51(4):416-423.

29. Malcolm RK, Fetherston SM, McCoy CF, Boyd P, Major I. Vaginal rings for delivery of HIV microbicides. Int J Womens Health. 2012;4:595-605. doi:10.2147/IJWH.S36282.

30. Nel AM, Haazen W, Nuttall JP, et al. Pharmacokinetics and Safety Assessment of Anti-HIV Dapivirine Vaginal Microbicide Rings with Multiple Dosing. J AIDS Clin Res. 2014;5(10):1000355. doi:10.4172/2155-6113.1000355.

31. Woolfson AD, Malcolm RK, Morrow RJ, Toner CF, McCullagh SD. Intravaginal ring delivery of the reverse transcriptase inhibitor TMC 120 as an HIV microbicide. Int J Pharm. 2006;325(1-2):82-89. doi:10.1016/j.ijpharm.2006.06.026.

32. Bell SEJ, Dennis AC, Fido LA, et al. Characterization of silicone elastomer vaginal rings containing HIV microbicide TMC120 by Raman spectroscopy. $J$ Pharm Pharmacol. 2007;59(2):203-207. doi:10.1211/jpp.59.2.0007.

33. Nel A, van Niekerk N, Kapiga S, et al. Safety and Efficacy of a Dapivirine Vaginal Ring for HIV Prevention in Women. N Engl J Med. 2016;375(22):2133-2143. doi:10.1056/NEJMoa1602046.

34. MacQueen KM, Weaver MA, van Loggerenberg F, et al. Assessing adherence in the CAPRISA 004 tenofovir gel HIV prevention trial: results of a nested casecontrol study. AIDS Behav. 2014;18(5):826-832. doi:10.1007/s10461-014-0753-8.

35. Abdool Karim Q, Abdool Karim SS, Frohlich JA, et al. Effectiveness and safety of tenofovir gel, an antiretroviral microbicide, for the prevention of HIV infection in women. Science. 2010;329(5996):1168-1174. doi:10.1126/science.1193748.

36. Kashuba ADM, Gengiah TN, Epi MS, et al. Genital Tenofovir Concentrations Correlate With Protection Against HIV Infection in the CAPRISA 004 Trial : Importance of Adherence for Microbicide Effectiveness. 2015;69(3):264-269.

37. Mauck CK, Straten A van der. Using objective markers to assess participant behavior in HIV prevention trials of vaginal microbicides. J Acquir Immune Defic 
Syndr. 2008;49(1):64-69. doi:10.1097/QAI.0b013e318183a917.

38. Minnis AM, Straten A Van Der, Salee P. Pre-exposure Prophylaxis Adherence Measured by Plasma Drug Level in MTN-001 : Comparison Between Vaginal Gel and Oral Tablets in Two Geographic Regions. AIDS Behav. 2015. doi:10.1007/s10461-015-1081-3.

39. Spence P, Nel A, van Niekerk N, Derrick T, Wilder S, Devlin B. Post-Use Assay of Vaginal Rings (VRs) as a Potential Measure of Clinical Trial Adherence. $J$ Pharm Biomed Anal. 2016;125:94-100. doi:10.1016/j.jpba.2016.03.023.

40. Stalter RM, Moench TR, MacQueen KM, Tolley EE, Owen DH, Consortium for Ring Adherence. Biomarkers and biometric measures of adherence to use of ARVbased vaginal rings. J Int AIDS Soc. 2016;19(1):20746. doi:10.7448/IAS.19.1.20746.

41. Tolley EE, Harrison PF, Goetghebeur E, et al. Adherence and its measurement in phase 2/3 microbicide trials. AIDS Behav. 2010;14(5):1124-1136. doi:10.1007/s10461-009-9635-x.

42. Amico KR, Mansoor LE, Corneli A, Torjesen K, Van Der Straten A. Adherence support approaches in biomedical HIV prevention trials: Experiences, insights and future directions from four multisite prevention trials. AIDS Behav. 2013;17(6):2143-2155. doi:10.1007/s10461-013-0429-9.

43. Owen DH, Katz DF. A vaginal fluid simulant. Contraception. 1999;59(2):91-95.

44. FDA. Guidance for Industry Vaginal Microbicides : Development for the Prevention of HIV Infection Guidance for Industry Vaginal Microbicides : Development for the Prevention of HIV Infection. https://www.fda.gov/downloads/Drugs/GuidanceComplianceRegulatoryInformatio n/Guidances/UCM328842.pdf. Published 2014.

45. Malcolm RK, Veazey RS, Geer L, et al. Sustained release of the CCR5 inhibitors CMPD167 and maraviroc from vaginal rings in rhesus macaques. Antimicrob Agents Chemother. 2012;56(5):2251-2258. doi:10.1128/AAC.05810-11.

46. Fetherston SM, Geer L, Veazey RS, et al. Partial protection against multiple RTSHIV162P3 vaginal challenge of rhesus macaques by a silicone elastomer vaginal ring releasing the NNRTI MC1220. J Antimicrob Chemother. 2013;68(2):394-403. doi: $10.1093 / \mathrm{jac} / \mathrm{dks} 415$.

47. Murphy DJ, Amssoms K, Pille G, et al. Sustained release of the candidate antiretroviral peptides T-1249 and JNJ54310516-AFP from a rod insert vaginal ring. 2016. doi:10.1007/s13346-015-0273-8.

48. Nel A, van Niekerk N, Kapiga S, et al. Safety and Efficacy of a Dapivirine Vaginal Ring for HIV Prevention in Women. N Engl J Med. 2016;375(22):2133-2143. doi:10.1056/NEJMoa1602046.

49. Moore JW, Flanner HH. Moore JW Pharm Tech 1996.pdf. Pharm Technol. 1996;20(6):64-74.

50. Costa P, Sousa Lobo JM. Modeling and comparison of dissolution profiles. Eur J Pharm Sci. 2001;13(2):123-133. doi:10.1016/S0928-0987(01)00095-1. 
51. Malcolm K, Woolfson D, Russell J, Tallon P, Mcauley L, Craig D. Influence of silicone elastomer solubility and diffusivity on the in vitro release of drugs from intravaginal rings. J Control Release. 2003;90(2):217-225.

52. Malcolm RK, Boyd PJ, McCoy CF, Murphy DJ. Microbicide vaginal rings: Technological challenges and clinical development. Adv Drug Deliv Rev. 2016;103:33-56. doi:10.1016/j.addr.2016.01.015.

53. Nel A, Haazen W, Nuttall J, Romano J, Rosenberg Z, van Niekerk N. A safety and pharmacokinetic trial assessing delivery of dapivirine from a vaginal ring in healthy women. AIDS. March 2014:1. doi:10.1097/QAD.0000000000000280.

54. Romano J, Variano B, Coplan P, et al. Safety and availability of dapivirine (TMC120) delivered from an intravaginal ring. AIDS Res Hum Retroviruses. 2009;25(5):483-488. doi:10.1089/aid.2008.0184.

55. Chen BA, Panther L, Marzinke MA, et al. Phase 1 Safety, Pharmacokinetics, and Pharmacodynamics of Dapivirine and Maraviroc Vaginal Rings: A Double-Blind Randomized Trial. J Acquir Immune Defic Syndr. 2015;70(3):242-249. doi:10.1097/QAI.0000000000000702.

56. Shah VP, Tsong Y, Sathe P, Liu JP. In vitro dissolution profile comparisonStatistics and analysis of the similarity factor, f2. Pharm Res. 1998;15(6):889-896. doi:10.1023/A:1011976615750.

57. Fox $\mathrm{C}$, Meldrum $\mathrm{S}$, Watson $\mathrm{B}$. Continuous measurement of $\mathrm{pH}$ by radio-telemetry of vaginal pH during human coitus. J Reprod Fertil. 1973;33(1940):69-75. 


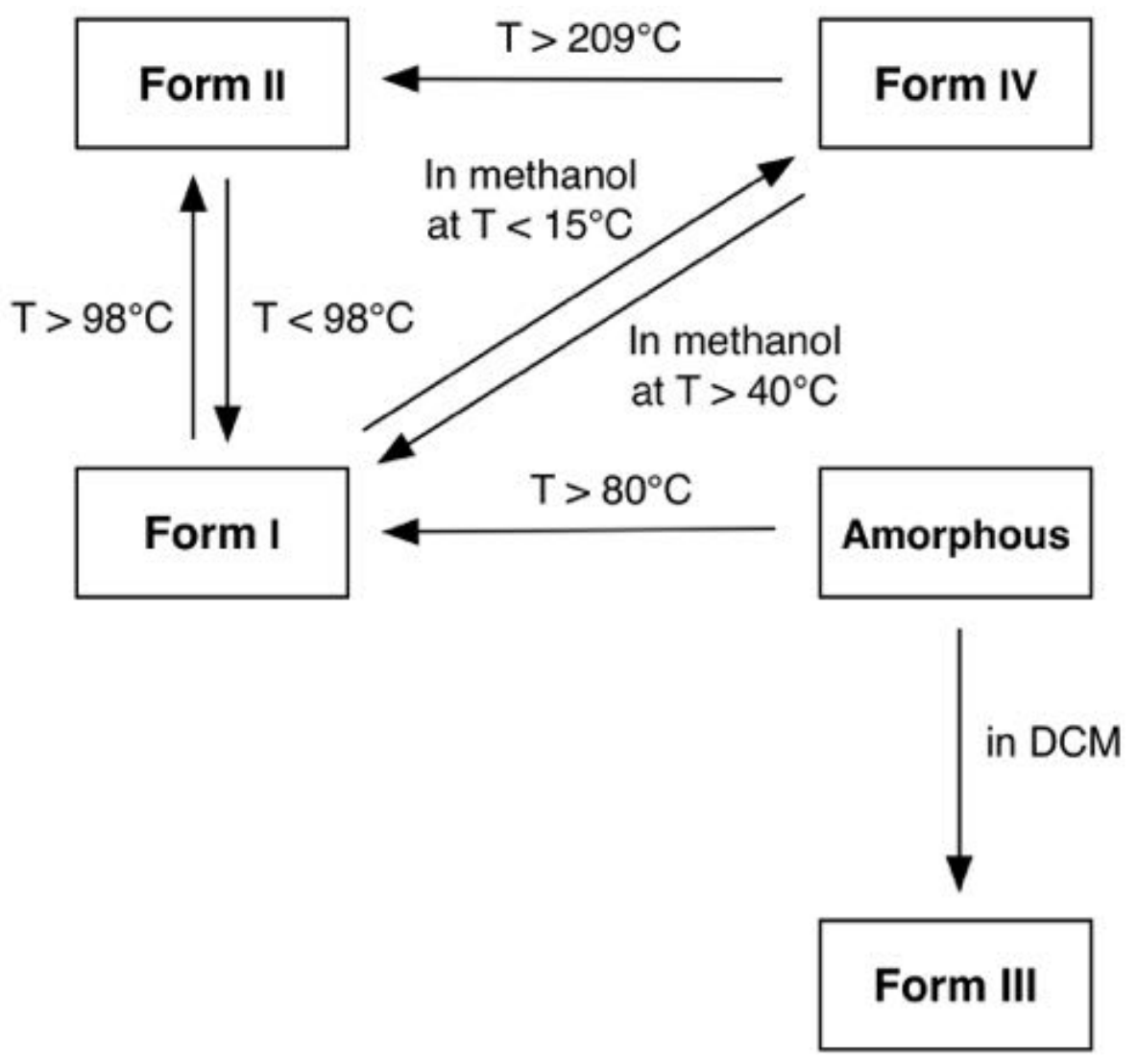

725 Figure 1. Summary of the relationships between the crystalline and amorphous 726 polymorphic forms of dapivirine. DCM = dichloromethane. Forms I and IV were 727 characterized by thermogravimetric analysis (TGA), differential scanning calorimetry 728 (DSC), polarized light microscopy, hot stage microscopy, x-ray powder diffraction 729 (XRPD), variable temperature XRPD (VT-XRPD) and single crystal x-ray diffraction. 730 Both forms were also tested by gravimetric vapour sorption (GVS) to assess 731 hygroscopicity, as well as solubility in common aqueous and organic solvents. 732 [Unpublished data; IPM]. 


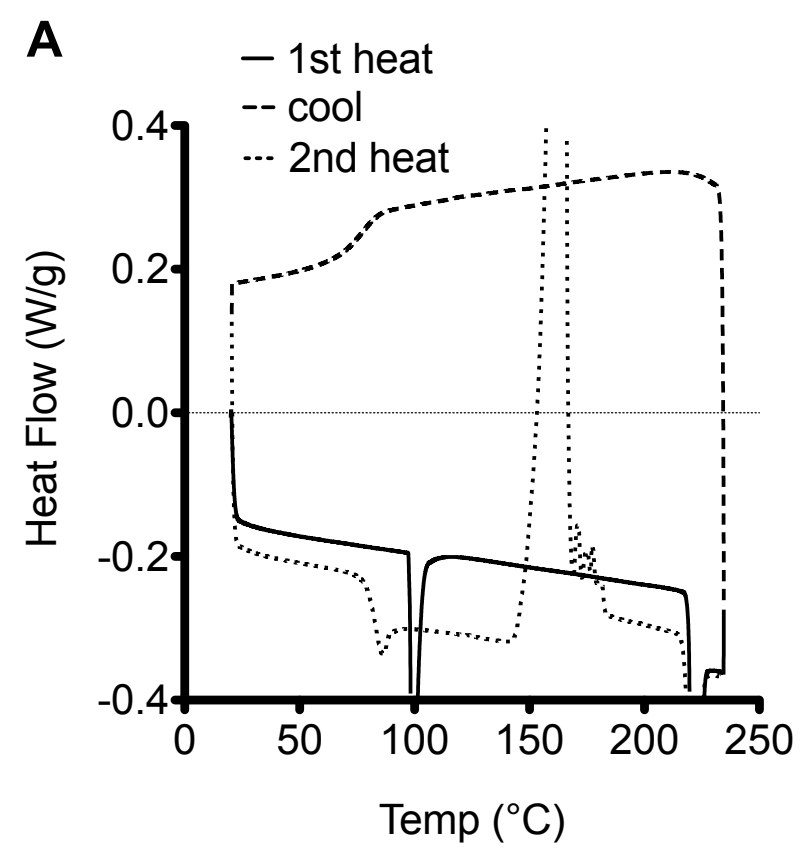

B

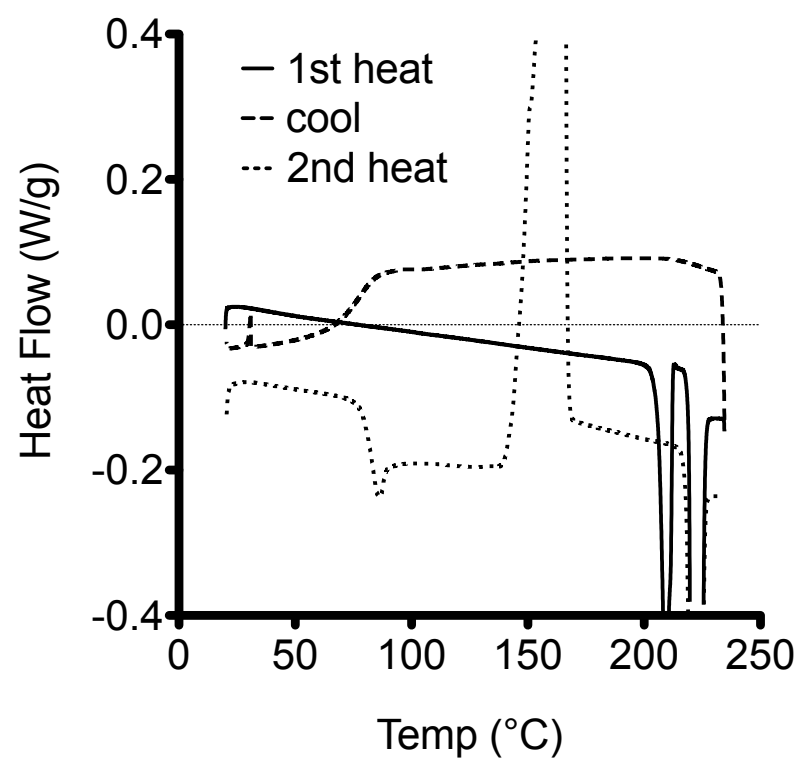

734 Figure 2. Representative DSC traces of non-micronized DPV (A) form I and (B) form IV.

735 For clarity, heat flow values between -0.4 and 0.4 are displayed, such that some peaks are 736 truncated. Values of the enthalpies associated with each endotherm and exotherm are 737 presented in Table 1 . The second heat cycle for form IV has been offset by $-0.1 \mathrm{~W} / \mathrm{g}$ to aid 738 visualisation. 

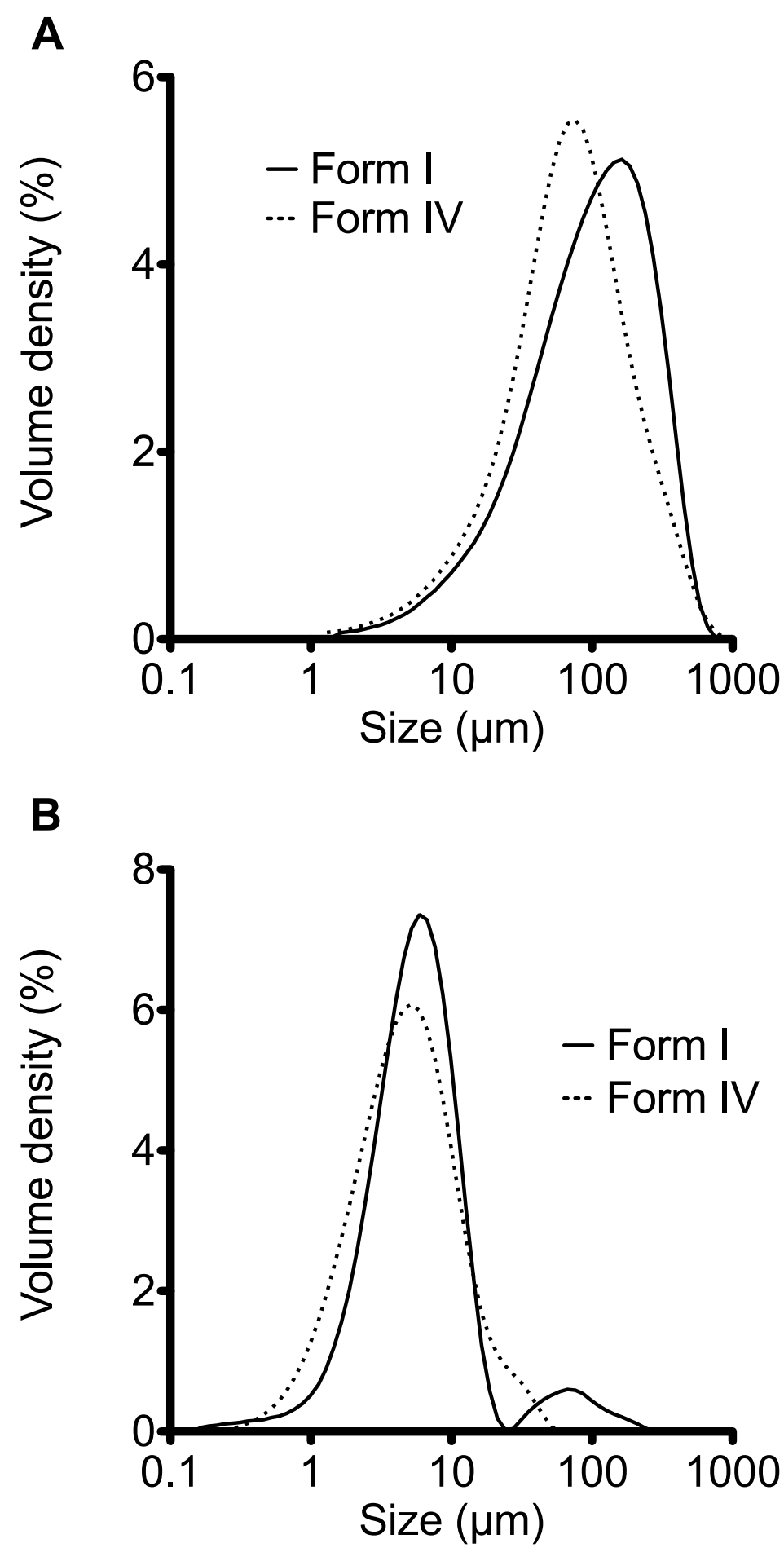

740 Figure 3. Measured particle size distribution of DPV form I and form IV. (A) non741 micronized powders; (B) micronized powders. 

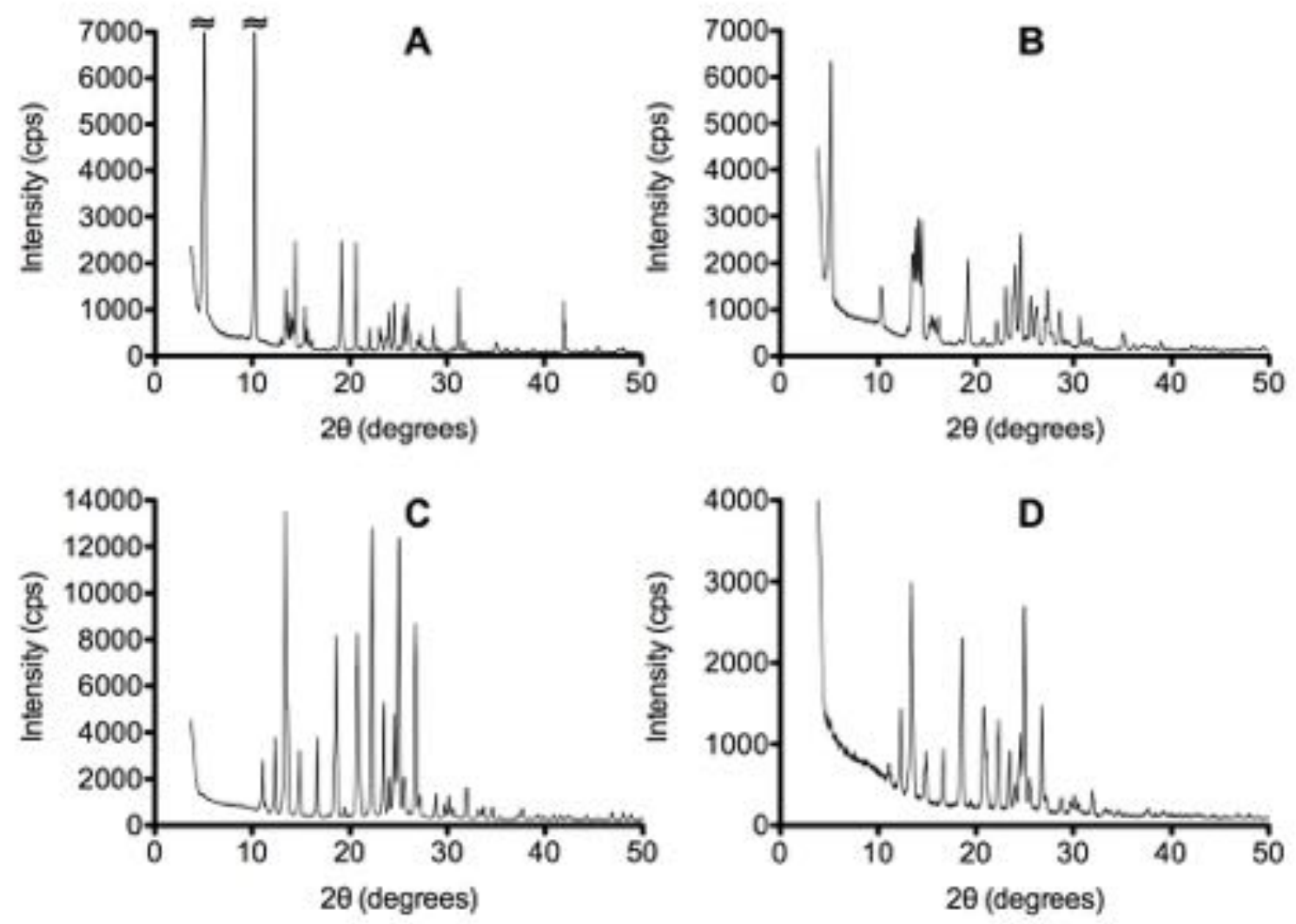

742

743 Figure 4. Powder XRD traces for (A) non-micronized DPV form I, (B) micronized DPV form I,

744 (C) non-micronized DPV form IV, and (D) micronized DPV form IV. Data is presented in the $2 \theta$

745 angular range of 3 to $50^{\circ}$. Two peaks in $A$, at $2 \theta=5.2$ and 10.3 degrees, have been truncated to 746 allow better comparison of the traces. 
748
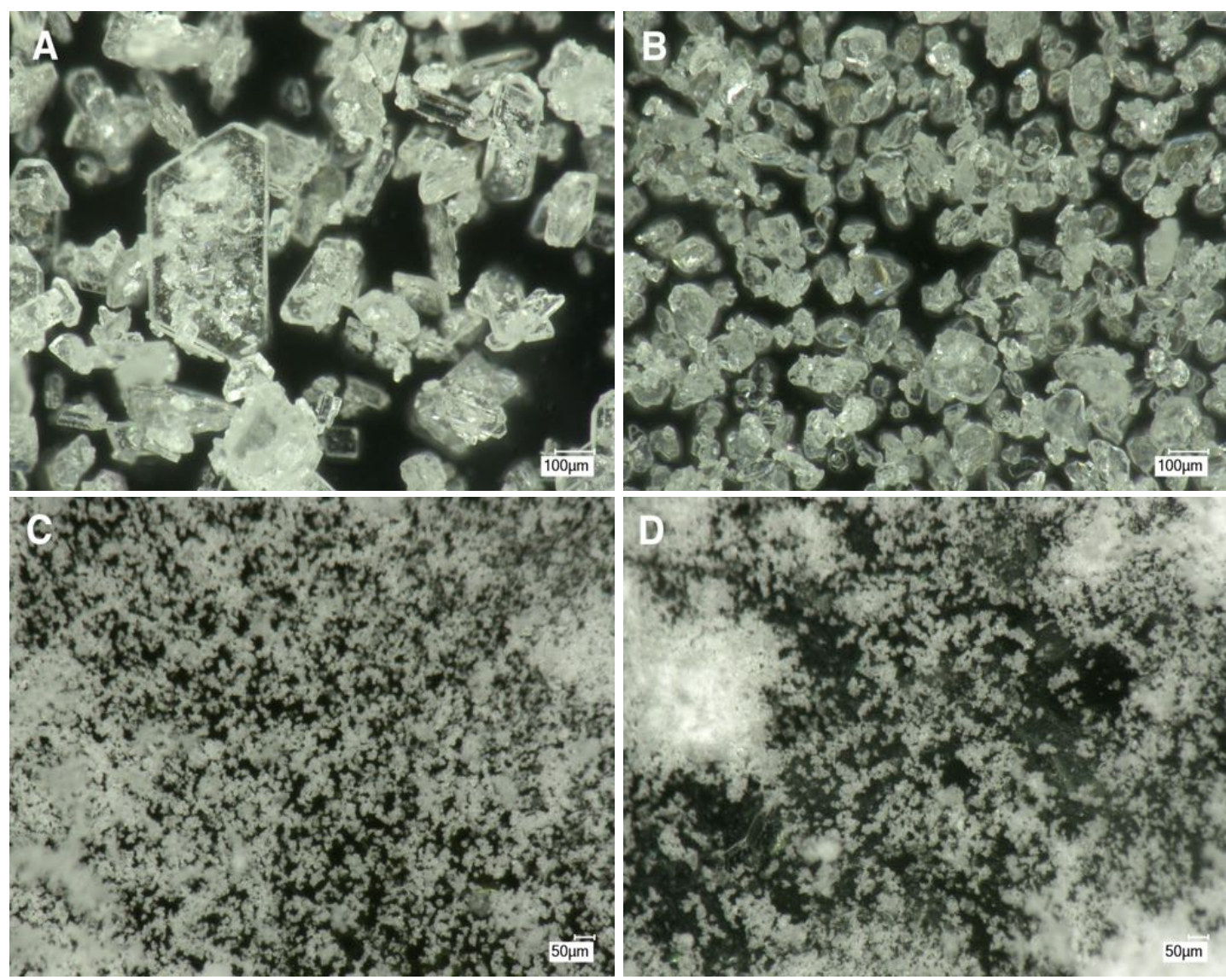

750

751 Figure 5. Representative micrographs recorded at 200x magnification of non-micronized DPV

752 form I (A), form IV (B), and micronized DPV form I (C) and form IV (D). 


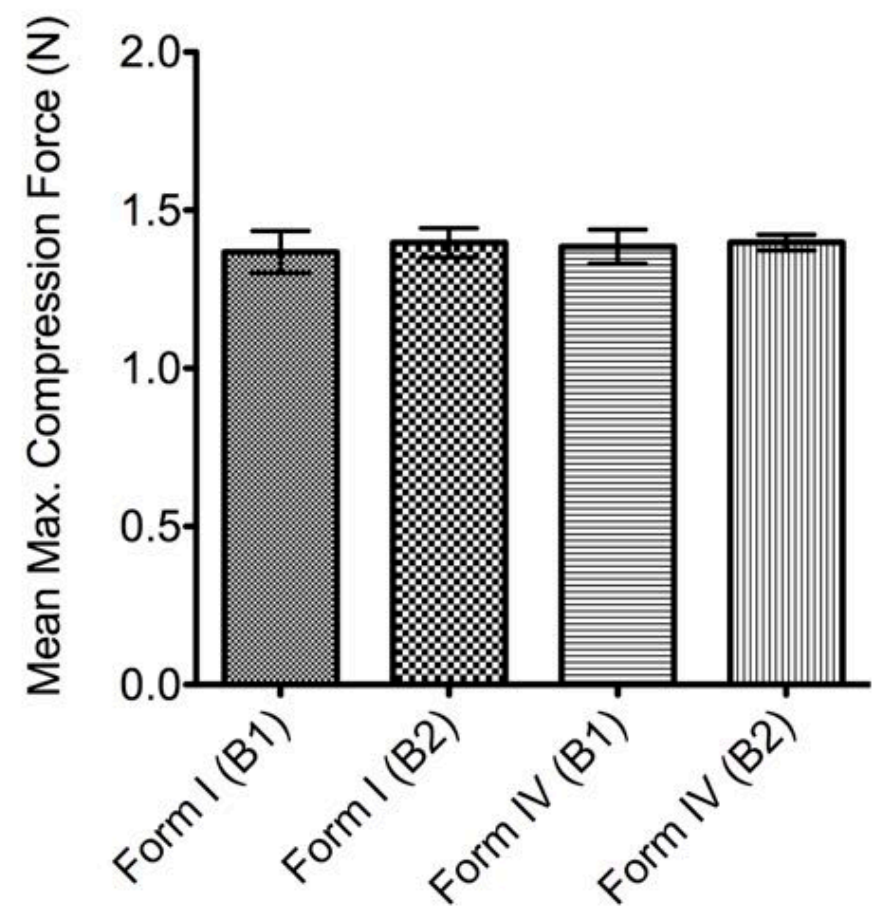

754 Figure 6. Mean maximum force required to compress each ring formulation ( $\mathrm{n}=5$ per batch). 

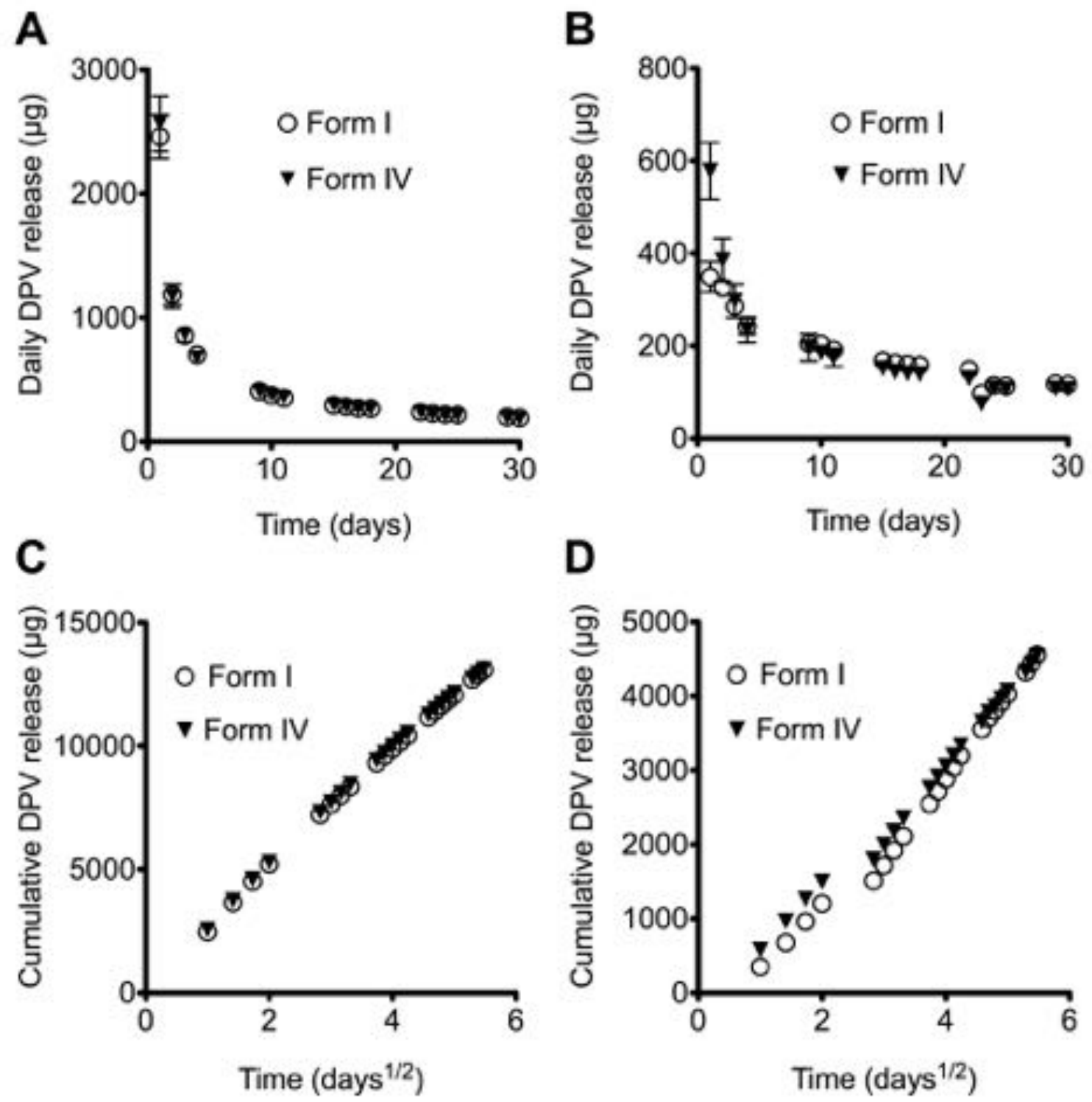

756 Figure 7. Mean daily release versus time profiles for release into (A) $\mathrm{IPA}+\mathrm{H}_{2} \mathrm{O}$ and (B) 757 SVF+Tween, and cumulative release versus root time profiles for release into (C) IPA $+\mathrm{H}_{2} \mathrm{O}$ and 758 (D) SVF+Tween, of DPV from MED-4870 matrix-type vaginal rings containing DPV (either form 759 I or form IV, $25 \mathrm{mg}$ per ring) over 30 days. Error bars in graphs A and B represent standard 760 deviation of twelve replicates; error bars were often smaller than the plot symbol. A small deviation 761 from the otherwise very consistent drug release profile is present on day 22 of the release into 762 SVF+Tween (B and D). This was due to an extended weekend release period without replacement 763 of release medium. 


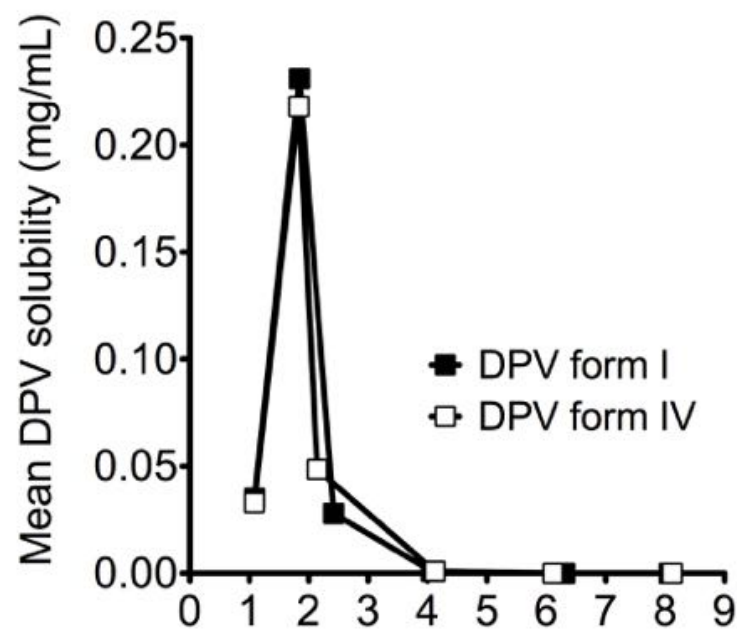

765

Final $\mathrm{pH}$ of medium

766 Figure 8. $\mathrm{pH}$ versus solubility profiles for DPV forms I and IV. Plot symbols represent the mean

767 of four replicates; error bars representing \pm standard deviation are smaller than the plot symbols. 
768 Table 1. Mean peak onset temperature $\left({ }^{\circ} \mathrm{C}\right)$, peak temperature $\left({ }^{\circ} \mathrm{C}\right)$ and enthalpy $(\Delta \mathrm{H}, \mathrm{J} / \mathrm{g})$ values 769 for each thermal transition associated with micronized and non-micronized DPV forms I and IV. 770 Endothermic transitions $1 \& 2$ are observed during the $1^{\text {st }}$ heat cycle, endothermic transitions $3 \&$ 7715 and exothermic transition 4 are observed during the $2^{\text {nd }}$ heat cycle.

\begin{tabular}{|c|c|c|c|c|c|}
\hline $\begin{array}{l}\text { DPV } \\
\text { material * }\end{array}$ & $\begin{array}{l}\text { Transition } \\
\text { No. }\end{array}$ & $\begin{array}{l}\text { Onset } \\
\left({ }^{\circ} \mathrm{C}\right)\end{array}$ & $\begin{array}{l}\text { Peak Maximum } \\
\left({ }^{\circ} \mathrm{C}\right)\end{array}$ & $\begin{array}{l}\text { Enthalpy } \\
(\Delta H, J / g)\end{array}$ & Assignment \\
\hline form I $(m)$ & 1 & 101.1 & 104.1 & 8.0 & $\mathrm{I} \rightarrow \mathrm{II}$ \\
\hline form I ${ }_{(\mathrm{nm})}$ & 1 & 97.8 & 99.3 & 10.4 & $\mathrm{I} \rightarrow \mathrm{I}$ \\
\hline form IV ${ }_{(\mathrm{nm})}$ & 1 & 205.8 & 209.3 & 10.9 & $\mathrm{IV} \rightarrow \mathrm{II}$ \\
\hline form IV $(m)$ & 1 & 189.4 & 199.0 & 8.0 & $\mathrm{IV} \rightarrow \mathrm{II}$ \\
\hline form I (m) & 2 & 219.9 & 221.9 & 114.7 & \multirow{4}{*}{ II melting } \\
\hline form I ${ }_{(n m)}$ & 2 & 219.9 & 221.9 & 119.2 & \\
\hline form IV $_{(\mathrm{nm})}$ & 2 & 220.0 & 221.8 & 121.9 & \\
\hline form IV $(m)$ & 2 & 220.1 & 221.8 & 104.2 & \\
\hline form I (m) & 3 & 80.9 & 85.6 & 1.6 & \multirow{4}{*}{$\begin{array}{l}\mathrm{T}_{\mathrm{g}} \text { with } \\
\text { amorphous } \\
\text { relaxation }\end{array}$} \\
\hline form I ${ }_{(n m)}$ & 3 & 80.9 & 85.5 & 1.8 & \\
\hline form IV $_{(\mathrm{nm})}$ & 3 & 81.2 & 85.6 & 1.4 & \\
\hline form IV $_{(m)}$ & 3 & 81.2 & 85.7 & 1.6 & \\
\hline form I (m) & 4 & 163.0 & 167.9 & -82.9 & \multirow{4}{*}{$\begin{array}{l}\text { Recrystallization } \\
\text { to form II }\end{array}$} \\
\hline form $I_{(\mathrm{nm})}$ & 4 & 159.8 & 167.4 & -87.4 & \\
\hline form IV ${ }_{(\mathrm{nm})}$ & 4 & 154.4 & 163.0 & -87.4 & \\
\hline form IV ${ }_{(m)}$ & 4 & 153.8 & 164.8 & -68.4 & \\
\hline form I (m) & 5 & 219.6 & 221.9 & 112.8 & \multirow{4}{*}{ II melting } \\
\hline form $I_{(n m)}$ & 5 & 219.5 & 221.7 & 117.0 & \\
\hline form IV $(\mathrm{nm})$ & 5 & 219.7 & 221.9 & 118.1 & \\
\hline form IV ${ }_{(m)}$ & 5 & 219.8 & 221.9 & 100.2 & \\
\hline
\end{tabular}


774 Table 2. Experimentally determined $d_{90}, d_{50}$ and $d_{10}$ values for both non-micronized and 775 micronized DPV form I and form IV materials with comparative certificate of analysis values 776 where available.

777

\begin{tabular}{|c|c|c|c|c|c|c|}
\hline \multirow{2}{*}{ DPV Batch * } & \multicolumn{3}{|c|}{$\begin{array}{l}\text { Experimentally Determined } \\
\text { Particle Size }(\mu \mathrm{m})\end{array}$} & \multicolumn{3}{|c|}{$\begin{array}{l}\text { CoA } A^{\#} \text { Specified Particle Sizze8 } \\
(\mu \mathrm{m})\end{array}$} \\
\hline & $d_{90}$ & $d_{50}$ & $d_{10}$ & $d_{90}$ & $d_{50}$ & $d_{10}$ \\
\hline form $I_{(n m)}$ & 324 & 111 & 22.1 & 302 & 101 & 19780 \\
\hline form I ${ }_{(m)}$ & 14.7 & 6.00 & 2.20 & 14.0 & 5.9 & 2.0781 \\
\hline form IV ${ }_{(\mathrm{nm})}$ & 250 & 74.4 & 17.8 & $N / A$ & $\mathrm{~N} / \mathrm{A}$ & N/A \\
\hline form IV $(m)$ & 14.5 & 5.00 & 1.58 & 14.6 & 4.82 & $0.55 \nabla 82$ \\
\hline
\end{tabular}

783 * $\mathrm{nm}$ - non-micronized, $\mathrm{m}$ - micronized; ${ }^{\#} \mathrm{CoA}$ - certificate of analysis 
784 Table 3. Mean ring weight, external diameter and cross-sectional diameter for five rings assessed

785 from each micronized DPV manufacturing batch.

786

\begin{tabular}{llll}
\hline $\begin{array}{l}\text { DPV polymorph } \\
\text { (Batch No.) }\end{array}$ & $\begin{array}{l}\text { Ring Weight } \\
\text { (Mean } \pm \text { SD; } g)\end{array}$ & $\begin{array}{l}\text { C.S.D. (Mean } \pm \\
\text { SD; mm) }\end{array}$ & $\begin{array}{l}\text { Mean Ex.D. } \pm \text { SD } \\
(\mathrm{mm})\end{array}$ \\
\hline form I (B1) & $7.93 \pm 0.24$ & $7.58 \pm 0.10$ & $56.41 \pm 0.04$ \\
form I (B2) & $7.99 \pm 0.01$ & $7.62 \pm 0.01$ & $56.41 \pm 0.03$ \\
form IV (B1) & $7.99 \pm 0.06$ & $7.62 \pm 0.01$ & $56.39 \pm 0.02$ \\
form IV (B2) & $8.05 \pm 0.01$ & $7.62 \pm 0.02$ & $56.39 \pm 0.02$ \\
\hline
\end{tabular}

787 B1 - batch 1, B2 - batch 2; acceptable limits for weight (7.2 - $8.8 \mathrm{~g})$, external diameter (Ex.D.; 54.9 - 57.1 mm) and 788 cross sectional diameter (C.S.D.; $7.3-8.1 \mathrm{~mm})$. 
790 Table 4. Mean Shore A hardness measurement for five rings assessed from each micronized DPV 791 manufacturing batch.

792

\begin{tabular}{ll}
\hline Batch Details & Shore A Hardness \pm SD (arbitrary units) \\
\hline DPV form I (B1) & $64.9 \pm 1.0$ \\
DPV form I (B2) & $65.1 \pm 0.5$ \\
DPV form IV (B1) & $65.1 \pm 0.3$ \\
DPV form IV (B2) & $65.7 \pm 0.2$ \\
\hline B1 - batch 1, B2 - batch 2
\end{tabular}

793 B1 - batch 1, B2 - batch 2

794 
795 Table 5. Release rates and coefficients of correlation $\left(\mathrm{r}^{2}\right)$ obtained from linear regression analysis 796 of the cumulative DPV release vs. root time plots for matrix-type vaginal rings containing different 797 forms of micronized DPV released into IPA $+\mathrm{H}_{2} \mathrm{O}$ or $\mathrm{SVF}+\mathrm{T}$ ween.

798

\begin{tabular}{|c|c|c|c|}
\hline DPV type & Release medium & Release rate $\left(\mu \mathrm{g} /\right.$ day $\left.^{0.5}\right)$ & $r^{2}$ value \\
\hline form I & $\mathrm{IPA}+\mathrm{H}_{2} \mathrm{O}$ & 2330 & 0.9983 \\
\hline form IV & $\mathrm{IPA}+\mathrm{H}_{2} \mathrm{O}$ & 2323 & 0.9980 \\
\hline form I & SVF+Tween & 959.9 & 0.9823 \\
\hline form IV & SVF+Tween & 887.8 & 0.9880 \\
\hline form I & SVF+Tween (day 8-30) & 1146.4 & 0.9993 \\
\hline form IV & SVF+Tween (day 8-30) & 1027.5 & 0.9995 \\
\hline
\end{tabular}


800 Table 6. Thermodynamic solubility values for DPV forms I and IV, micronized and non801 micronized, into SVF $+0.2 \%$ Tween 80 and 1:1 v/v IPA/water. Both release media have been 802 used routinely throughout the development process for the DPV-releasing vaginal ring. 803 Solubility values are reported as mean $\pm \mathrm{SD}$ of $\mathrm{n}=4$ replicates.

804

\begin{tabular}{llll}
\hline $\begin{array}{l}\text { DPV } \\
\text { polymorph }\end{array}$ & Solvent system & $\begin{array}{l}\text { DPV solubility at } 37^{\circ} \mathrm{C} \\
(\text { Mean } \pm \text { SD; } \mu \mathrm{g} / \mathrm{mL})\end{array}$ & $\begin{array}{l}\text { PXRD analysis of } \\
\text { residual solid }\end{array}$ \\
\hline form I $_{(\mathrm{nm})}$ & SVF $+0.2 \%(\mathrm{w} / \mathrm{v})$ Tween 80 & $16.78 \pm 0.66$ & form I \\
form I $_{(\mathrm{m})}$ & SVF $+0.2 \%(\mathrm{w} / \mathrm{v})$ Tween 80 & $16.12 \pm 0.29$ & form I \\
form I $_{(\mathrm{nm})}$ & IPA/water $(1: 1 \mathrm{v} / \mathrm{v})$ & $1171 \pm 53$ & form I \\
form I $_{(\mathrm{m})}$ & IPA/water $(1: 1 \mathrm{v} / \mathrm{v})$ & $1249 \pm 46$ & form I \\
form IV $_{(\mathrm{nm})}$ & SVF $+0.2 \%(\mathrm{w} / \mathrm{v})$ Tween 80 & $14.74 \pm 0.99$ & form IV \\
form IV & form IV \\
form IV $_{(\mathrm{nm})}$ & SVF $+0.2 \%(\mathrm{w} / \mathrm{v})$ Tween 80 & $15.83 \pm 0.14$ & form IV \\
form IV $_{(\mathrm{m})}$ & IPA/water $(1: 1 \mathrm{v} / \mathrm{v})$ & $1193 \pm 36$ & form IV \\
\hline
\end{tabular}


807 Table 7. Amount of DPV released, residual DPV content and calculated initial content values for $80825 \mathrm{mg}$ (nominally) DPV polymorph rings.

809

\begin{tabular}{lllll}
\hline $\begin{array}{l}\text { DPV } \\
\text { polymorph }\end{array}$ & Release medium & DPV released $(\mathbf{m g})$ & Residual DPV (mg) & $\begin{array}{l}\text { Calculated initial } \\
\text { DPV content }(\mathbf{m g})\end{array}$ \\
\hline form I & $\mathrm{IPA}+\mathrm{H}_{2} \mathrm{O}$ & $13.1 \pm 0.2$ & $12.0 \pm 0.3$ & $25.1 \pm 0.4$ \\
form IV & $\mathrm{IPA}+\mathrm{H}_{2} \mathrm{O}$ & $13.1 \pm 0.5$ & $12.6 \pm 0.3$ & $25.7 \pm 0.3$ \\
form I & SVF+Tween & $4.6 \pm 0.1$ & $20.3 \pm 0.4$ & $24.9 \pm 0.3$ \\
form IV & SVF+Tween & $4.5 \pm 0.4$ & $21.3 \pm 0.4$ & $25.9 \pm 0.5$
\end{tabular}

